Original Research Paper

\title{
Dreams, Possibilities and Necessity of Public Education through Urban Students' Eyes: It is the Climate
}

\author{
Dolapo Adeniji-Neill and Devin G. Thornburg \\ Curriculum and Instruction, Adelphi University, United States
}

Article history

Received: 16-01-2018

Revised: 13-03-2018

Accepted: 21-03-2018

Corresponding Author:

Dolapo Adeniji-Neill

Curriculum and Instruction,

Adelphi University, United

States

Email: dolapo.neill@gmail.com

\begin{abstract}
School climate is the quality and character of school life. It provides a shared sense of purpose, as well as norms and values that may serve to bind or tear apart the fabric and foundation of a school. In a broader sense, school culture is based on the partnership, cohesiveness and collaborations between "town and gown" - a colloquial term referring to the relationship between schools and communities, students, parents, faculty, administration and staff. Due to such a broad scope, it affects teaching, learning and organizational structures. Key factors affecting school culture may include, but are not limited to, perceptions of personal safety, interpersonal relationships, teaching, learning, as well as the external environment.
\end{abstract}

Keywords: School Climate, Character of School, School Culture, Teaching, Learning, Personal Safety

\section{Introduction}

\section{Literature Review}

Let America be the dream the dreamers dreamed- Let it be that great strong land of love where never kings connive nor tyrants scheme that any man be crushed by one above. (It never was America to me.) O, let my land be a land where Liberty Is crowned with no false patriotic wreath, But opportunity is real and life is free, Equality is in the air we breathe. - Let America Be America Again (1935), Langston Hughes.

School climate research is a well-trodden path in education and it has been defined as the atmosphere, ethos, tone, ideology, community, personality or milieu of a school (Hoy, 2008). It also affects how one feels about the school and the people involved in the school (Davis and Peck, 1992) and has great influence on how one feels about experiences in a school (Lindelow et al., 1989). The term 'school climate' is sometimes used interchangeably with 'school culture', although many believe that there is a clear and very meaningful distinction between the two. More specifically, while culture pertains to the cumulative 'state' of the school, its norms, implicit rules, practices and beliefs, the perceptions, attitudes and feelings about the school environment define school climate (NSCC, 2015; Gruenert, 2008). In this work, it is further argued that understanding more about the complex interplay of school climate and culture will help to illuminate the ways in which schools can improve.

Poor school climate is correlated with absenteeism (Reid, 1982), suspension rates (Wu et al., 1982) and higher school dropout rates (Anderson, 1982). Extant research has further confirmed that students who do not graduate from high school face increased risk of unemployment, poverty, poor health and involvement in the criminal justice system Conversely, empirical evidence indicates that schools that demonstrate a positive school climate have better attendance and higher morale (Bryk and Driscoll, 1988), as well as demonstrate greater academic effectiveness (Borger, 1985; Shindler et al., 2009a). These schools are also a place where self-worth, pride, respect and trust are fostered.

Gangi (2009) surmised that the findings from eminent collaborative organizations reveal an enormous discrepancy between current empirical research on positive school climate and what is actually currently being done in schools, in state and federal education departments, as well as in colleges and universities where teachers are educated. The overall consensus is thus that the "gap between school climate research, policy, practice and teacher education is socially unjust and a violation of children's human rights" (Cohen et al., 2009).

Again, we would argue that this discrepancy between research and practice is partly due to the inability to make a distinction between school climate and school culture - both in terms of identification of factors and forms of intervention. While much of the extant research on school climate has involved surveys of students along 
with other stakeholders, studies that have been conducted on school culture typically focused on the perspectives of administration, faculty and staff. Thus, in order to address this gap in the extant knowledge, our research on school climate is conducted with the students at its focus. Moreover, the study participants are asked open-ended questions, allowing them to discuss what they see as important factors and interventions in their schools.

Hoy et al. (1991) research confirmed that a great many schools across the nation fit the description of an unhealthy school. Schools with a negative school climate prevent teachers, support staff and administration from being able to model positive citizen-forming behaviors for our students (Collaborative for Academic, Social and Emotional Learning (Casel.org, 2018).

Findings reported by Kana'iaupuni et al. (2010) indicated that schools with a negative climate send out negative signals to at-risk students. This often results in instilling the perception that they are unworthy and unable to continue in the educational process. In an earlier study, Bearden et al. (1989) confirmed that students' perception of themselves, along with the school experience, are paramount to school values and practices, since a negative school climate could actually decrease a student's motivation for learning. According to Hoy and Tarter (1997), unhealthy schools are deterred in their mission and goals by parental and public demands. Unhealthy schools lack an effective leader and the teachers are generally unhappy with their jobs and colleagues. In addition, neither teachers nor students are academically motivated, as academic achievement is not highly valued in poor schools. In contrast, healthy schools that promote high academic standards, appropriate leadership and collegiality provide a climate more conducive to student success and achievement (Hoy et al., 1991).

Social and emotional learning helps students develop fundamental and effective life skills, including recognizing and managing emotions, developing caring and concern for others, establishing positive relationships, making responsible decisions and handling challenging situations constructively and ethically. Such skills help prevent negative behaviors and the disciplinary consequences that may result when students do not live up to behavioral standards (Casel.org, 2008).

\section{Methodology}

The purpose of this research was to examine, through students' perspectives, the key factors affecting school culture, namely a person's perception of his/her personal safety, interpersonal relationships, teaching and learning, as well as the external environmental factors affecting learning and students' well-being.

In order to answer our research questions presented below, we fist examined the publicly available records pertaining to the school our study focuses on, which is a part of the school district in New York. More specifically, we looked at the report on teachers, administration and students' performance for the year 2012-2013 and extracted the data germane to our research questions. We also distributed survey questions to the students, which resulted in 397 responses. It is important to note that, at the time of this research, the urban 9-12 School we researched was undergoing leadership and staff transition. Thus, we sought input from the students to help determine a new direction for their school, as well as establish how they feel in general about being a member of their school community. Survey questionnaires were distributed to students in grades 9-12.

The research questions guiding this study were:

1. WISH: What do you wish we had at our school and why?

2. CHANGE: Do you think students can change to make our school better, if so how?

3. FEEL: How do you feel about your classes? What makes you feel this way?

4. IMAGINE: If you could imagine our school differently, give an idea of what our school would be like?

\section{Participants' Demographic Information}

The participants of this survey were 9-12 grade high school students attending the same urban school. Their records revealed that $20 \%$ of student population possess limited English proficiency. In terms of their racial background, $50 \%$ of students define as Black or African American, $49 \%$ as Hispanic or Latino and the remaining $1 \%$ comprises those declared as White or 'Other'. In the 2010-2011 academic year, the school served 1,666 students and reported $84 \%$ annual attendance rate. Finally, $34 \%$ of student population are eligible for free or reducedprice lunch, indicating low socio-economic status. Average class size varies by subject and was 25 for Math and Social Studies, 21 for English and 16 for Science.

\section{Teacher Qualifications}

In 2010-2011, the school employed 93 teachers, of whom $73 \%$ have master's degree and work 30 hours or more and $97 \%$ have more than 3 years of experience. In addition, in this academic year, 97\% of classes were taught by Highly Qualified.

Teachers and the school reported $84 \%$ annual attendance rate, along with $14 \%$ student suspension rate. Finally, turnover rate of teachers with fewer than five years of experience was $67 \%$. It should be noted that, for the specified school year, Teacher Turnover Rate is calculated as the number of teachers in that school year who were not teaching in the following school year, divided by the number of teachers in the specified school year, expressed as a percentage. 


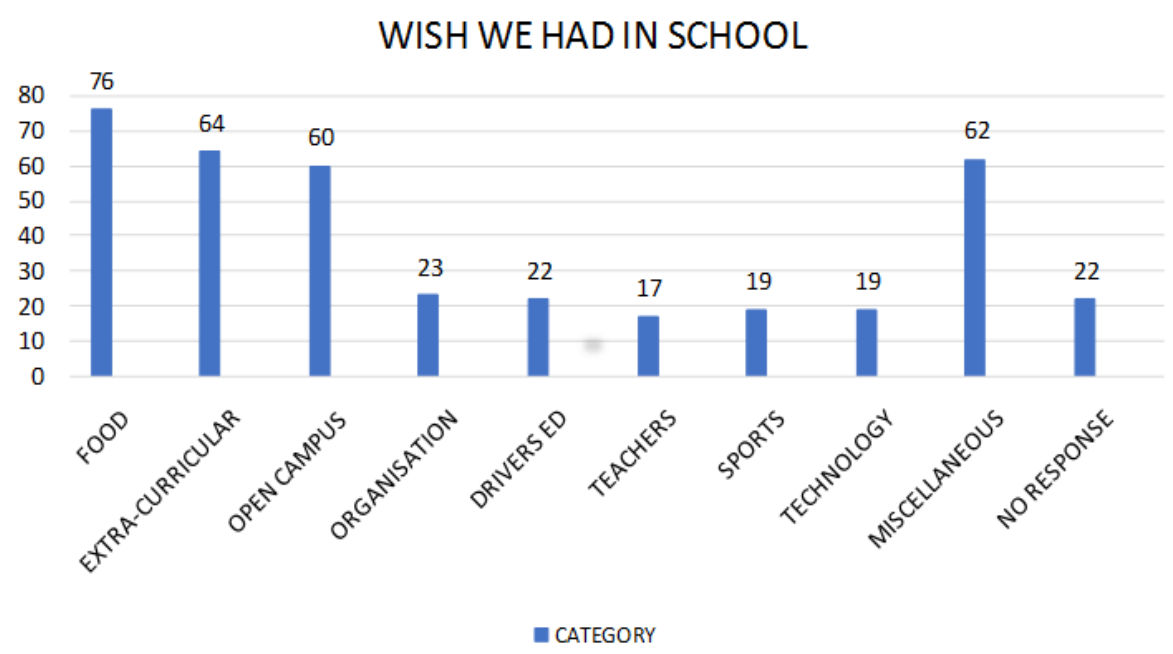

Fig. 1: Number of responces for what we wish we had in school

Table 1: WHAT DO YOU WISH WE HAD AT OUR SCHOOL?

\begin{tabular}{lcccc}
\hline CATEGORY & $9^{\mathrm{TH}}(\mathrm{n}=65)$ & $10^{\mathrm{TH}}(\mathrm{n}=101)$ & $11^{\mathrm{TH}}(\mathrm{n}=128)$ & $12^{\mathrm{TH}}(\mathrm{n}=103)$ \\
\hline FOOD & 25 & 11 & 25 & 15 \\
EXTRA-CURRICULAR & 4 & 21 & 25 & 14 \\
OPEN CAMPUS & 9 & 22 & 16 & 13 \\
ORGANISATION & 1 & 11 & 6 & 5 \\
DRIVERS ED & 1 & 6 & 6 & 9 \\
TEACHERS & 3 & 5 & 6 & 3 \\
SPORTS & 3 & 5 & 5 & 6 \\
TECHNOLOGY & 1 & 3 & 8 & 7 \\
MISCELLANEOUS & 10 & 7 & 20 & 25 \\
NORESPONSE & 8 & 10 & 11 & 6 \\
TOTAL & 65 & 101 & 128 & 103 \\
\hline
\end{tabular}

In public schools, teachers that teach one class outside of the certification area(s) are recognized as Highly Qualified provided that:

- The teacher had been determined by the school or district through the HOUSSE process or other stateaccepted methods to have demonstrated acceptable subject knowledge and teaching skills and

- The class in question was not the sole assignment reported. Credit for incidental teaching does not extend beyond a single assignment. Independent of Highly Qualified Teacher status, any assignment for which a teacher did not hold a valid certificate still registers as teaching out of certification

\section{Data Analysis}

In response to the question "What do you wish we had at our school and why?" the students responded with many suggestions,(As seen in Fig. 1 and Table 1) which are presented below, with those most frequently cited presented first:
1. FOOD
2. EXTRA-CURRICULAR
3. OPEN CAMPUS
4. MISCELLANEOUS
5. ORGANIZATION
6. DRIVERS ED
7. NO RESPONSE
8. SPORTS
9. TECHNOLOGY
10. TEACHERS

In addition to these, students also proposed:

- Materials

- Safety

- School Trips

- Cleanliness

- Tutoring

- Bus

Figure 1 and Table 1 student responses $(N=397)$ to the question "WISH: What do you wish we had at our school and why?" 
While the students provided a broad range of responses, it is evident that 10 issues in particular are crucial to them. For example, they wished for a food court style cafeteria, with healthy foods, amongst other important changes. They commented, "We need better lunch because some of the lunch is not good and not healthy." When commenting on teachers, one student wrote, "I wish teachers would challenge us more. I wish we had a better school curriculum." When asked about OPEN CAMPUS, one respondent noted, "I wish we could go outside and have better lunch because we need fresh air and more kids would eat." SPORTS, elicited a response, "We need Friday night lights for football, baseball, soccer, all outdoor-sports. It will be more fun and exciting. Also better fields and we do need new bleachers." On MATERIALS, one student commented: "We need better textbooks and books to read." TECHNOLOGY elicited the following comment from one student: "I wish this school had new boards, like marker boards or smartboards. Also new computers." SAFETY was also deemed important, as noted in this comment: "We need better security so if a fight breaks loose then we could feel safe." DRIVERS' ED was also among the key issues, as one student stated: "I wish we had drivers' ed, so that students my age can learn the ins and outs of driving so they can get their licenses." ORGANIZATION elicited the following response: "We need more time to get between classes. We certainly should have uniforms, so we don't have to worry about what we are wearing." Finally, students were provided space to write MISCELLANEOUS comments, one of which was: "The bathrooms need to be clean. We should have buses because I have to walk so long to come to school. I wish we had a study hall where students could converge with their teacher and receive tutoring/homework help during the school day."

Research Question 2 pertained to CHANGE and was "Do you think students can change to make our school better, if so how?"

The students' responses $(N=397)$ could be classified into the following categories as mentioned in Table 2.

\section{STUDENTS \\ 2. VIOLENCE \\ 3. MORE ACTIVITIES \\ 4. DISCIPLINE \\ 5. NO RESPONSE \\ 6. TEACHERS \\ 7. REWARD GOOD BEHAVIOR MISCELLANEOUS}

Among the miscellaneous responses, the most prominent were:

\section{UNIFORMS \\ 2. VOICING OPINION \\ 3. SAFETY}

Students also provided comments that further elucidated their responses. Some examples are given below:

- LESS VIOLENCE: "I would like a school to be with no fights and a place we can learn."

- SAFETY: "A better, safe and secure school. More civilized, more control."

- BETTER ACADEMICS: "Our school would be a place that other students from other schools would want to come to. Where everyone gets along and students are graduating with high GPA's."

- MORE ACTIVITIES: "Learning would be more fundamental and more interesting and more activities for everyone to be interested in."

- CLEANER SCHOOL: "Nice grass with flowers, clean bathrooms, colorful walls and big giant trees."

- OPEN CAMPUS: "I can imagine a good school and have the privilege to go out and come back for class during lunch time."

- TECHNOLOGY: "Everyone would have laptops and the school with the latest technology."

- MISCELLANEOUS: "With the modifications, I can see this school become successful."

Table 2: DO YOU THINK STUDENT CAN CHANGE TO MAKE OUR SCHOOL BETTER?

\begin{tabular}{lcccc}
\hline CATEGORY & $9^{\mathrm{TH}}(\mathrm{n}=65)$ & $10^{\mathrm{TH}}(\mathrm{n}=101)$ & $11^{\mathrm{TH}}(\mathrm{n}=128)$ & $12^{\mathrm{TH}}(\mathrm{n}=103)$ \\
\hline STUDENTS & 23 & 32 & 51 & 31 \\
VIOLENCE & 13 & 10 & 14 & 15 \\
MORE ACTIVITIES & 4 & 21 & 12 & 11 \\
DISCIPLINE & 2 & 9 & 9 & 13 \\
TEACHERS & 5 & 9 & 6 & 0 \\
REWARD GOOD BEHAVIOR & 5 & 7 & 3 & 6 \\
MISCELLANEOUS & 5 & 5 & 12 & 17 \\
NO RESPONSE & 8 & 101 & 128 & 103 \\
TOTAL & 65 & & & \\
\hline
\end{tabular}

Table 3: CAN STUDENT CHANGE?

\begin{tabular}{lllll}
\hline CAN STUDENT CHANGE & $9^{\mathrm{TH}}(\mathrm{n}=65)$ & $10^{\mathrm{TH}}(\mathrm{n}=101)$ & $11^{\mathrm{TH}}(\mathrm{n}=128)$ & $12^{\mathrm{TH}}(\mathrm{n}=103)$ \\
\hline YES & $66 \%(43)$ & $64 \%(65)$ & $81 \%(104)$ & $52 \%(54)$ \\
NO & $34 \%(18)$ & $36 \%(34)$ & $19 \%(12)$ & $48 \%(31)$ \\
\hline
\end{tabular}


Table 4: How do you feel about your classes? What makes you feel this way?

\begin{tabular}{lllll}
\hline CATEGORY & $9^{\mathrm{TH}}(\mathrm{n}=65)$ & $10^{\mathrm{TH}}(\mathrm{n}=101)$ & $11^{\mathrm{TH}}(\mathrm{n}=128)$ & $12^{\mathrm{TH}}(\mathrm{n}=103)$ \\
\hline TEACHERS & 27 & 37 & 41 & 29 \\
MORE ENGAGING & 18 & 24 & 25 & 21 \\
STUDENTS & 3 & 10 & 19 & 15 \\
OVER- CROWDING & 2 & 6 & 9 & 8 \\
MATERIAL & 6 & 5 & 5 & 3 \\
NEW CLASSES & 1 & 4 & 5 & 3 \\
MISCELLANEOUS & 4 & 13 & 16 & 10 \\
NO RESPONSE & 4 & 2 & 7 & 14 \\
TOTAL & 65 & 101 & 128 & 103 \\
\hline
\end{tabular}

\section{Can student change}

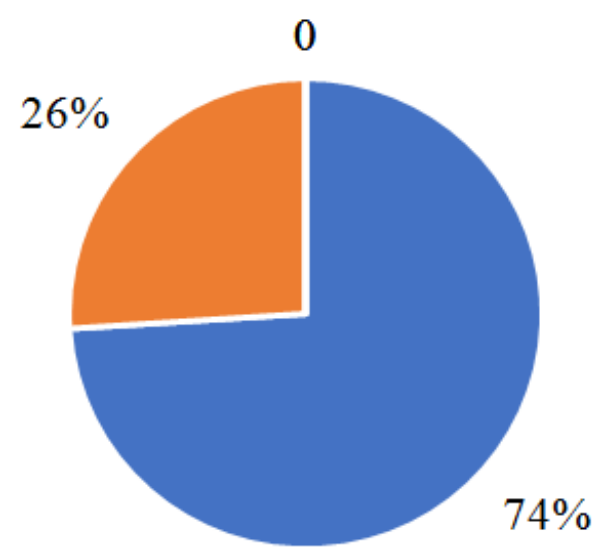

- YES $-\mathrm{NO}$

Fig. 2: Total \% of repondses -can student change

Table 3 and Fig. 2 illustrated how student feel about their own attitude towards their school. Majority of the students believe that if everything else falls into place as shown in Table 1 and 2, there is a definite hope for better attitude towards school and schooling. Majority of the students believe that attitudes of their peers can change from negative to positive if school climate change; if students feel safe, and if curricula and faculty also become student centered.

Research Question 3 asked the students "How do you feel about your classes? What makes you feel this way?"

Again, the students' responses $(N=397)$ could be classified into the following categories as shown in Fig. 3 and Table 4.

1. TEACHERS

2. MORE ENGAGING

3. STUDENTS

4. MISCELLANEOUS

5. NO RESPONSE

6. OVERCROWDING

7. MATERIALS

\section{NEW CLASSES}

Student's comments regarding the questions: Do you like your classes (Table 5 and Fig. 4) are::

- TEACHERS: "The classes are great, but the teachers are always saying and stressing over what the students do wrong. They never praise and regard the students on what they do right! That makes them not want to do good things."

- MORE ENGAGING: "My classes are boring because all we do is just copy stuff on the board and memorize it."

- STUDENTS: "I feel that all of my classes are fine but the matter of respect for the teachers and the students need to change."

- OVERCROWDING: "I feel that some of my classes are too large and there are students who are not interested in learning and disrupts my learning."

- MATERIALS: "I feel that we need better computers and textbooks because with better textbooks you don't have to get the ones that are nasty."

- NEW CLASSES: "I think that my classes are alright but I think they should be geared towards my future career."

- MISCELLANEOUS: "I feel that some of my classes are unnecessary, because I'm not going to use this in my everyday life and I'm not learning about my culture."

- In line with Research Question 4, we asked students to "imagine" what their school could be like. Their responses are given below, grouped by frequency and by class they attend.

- LESS VIOLENCE: "I would like a school to be with no fights and a place we can learn."

- SAFETY: "A better, safe and secure school. More civilized, more control."

- BETTER ACADEMICS: "Our school would be a place that other students from other schools want to come to. Where everyone gets along and students are graduating with high GPA's."

- MORE ACTIVITIES: "Learning would be more fundamental and more interesting and more activities for everyone to be interested in."

- CLEANER SCHOOL: "Nice grass with flowers, clean bathrooms, colorful walls and big giant trees." 
- OPEN CAMPUS: "I can imagine a good school and have the privilege to go out and come back for class during lunch time."

- TECHNOLOGY: "Everyone would have laptops and the school with the latest technology."

- MISCELLANEOUS: "With the modifications, I can see this school become successful."
In Fig. 5 and Table 6, students imagine a school with less violence and a feeling of security. They want a space where learning is less of a chore but something they look forward to and crave. They want things that affluent schools take for granted, clean schools, technology in the classroom and extracurricular activities like sports and clubs.

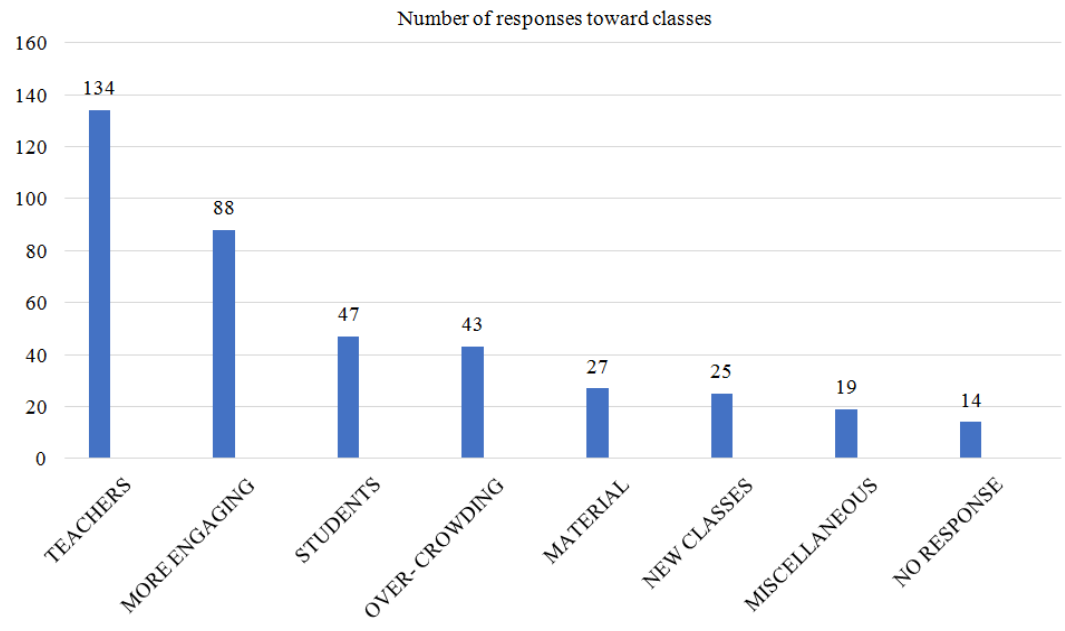

Fig. 3: Total number of responses towards classes

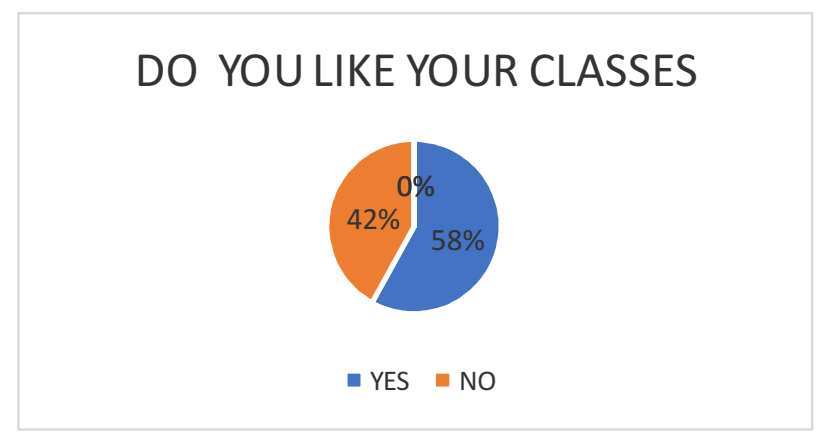

Fig. 4: Percenage of people who like classes

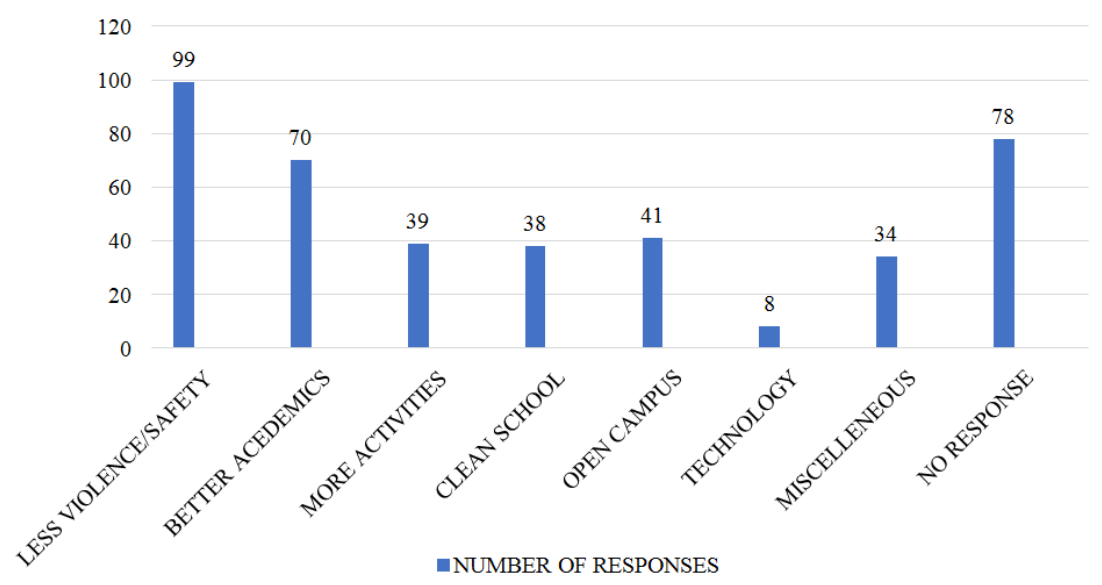

Fig. 5: If you could imagine our school differently, what would our school be like? 
Table 5: Do You Like Your Classes?

\begin{tabular}{lllll}
\hline DO YOU LIKE YOUR CLASSES & $9^{\mathrm{TH}}(\mathrm{n}=65)$ & $10^{\mathrm{TH}}(\mathrm{n}=101)$ & $11^{\mathrm{TH}}(\mathrm{n}=128)$ & $12^{\mathrm{TH}}(\mathrm{n}=103)$ \\
\hline YES & 36 & 59 & 59 & 50 \\
NO & 25 & 40 & 52 & 39 \\
\hline
\end{tabular}

Table 6: If you could imagine our school differently, what would our school be like?

\begin{tabular}{lllll}
\hline CATEGORY & $9^{\mathrm{TH}}(\mathrm{n}=65)$ & $10^{\mathrm{TH}}(\mathrm{n}=101)$ & $11^{\mathrm{TH}}(\mathrm{n}=128)$ & $12^{\mathrm{TH}}(\mathrm{n}=103)$ \\
\hline LESS VIOLENCE/SAFETY & 16 & 27 & 29 & 27 \\
BETTER ACEDEMICS & 7 & 14 & 31 & 18 \\
MORE ACTIVITIES & 6 & 10 & 15 & 8 \\
CLEAN SCHOOL & 7 & 7 & 15 & 4 \\
OPEN CAMPUS & 10 & 7 & 10 & 1 \\
TECHNOLOGY & 5 & 0 & 2 & 8 \\
MISCELLANEOUS & 4 & 12 & 10 & 28 \\
NO RESPONSE & 10 & 24 & 16 & 103 \\
TOTAL & 65 & 101 & 128 & 9 \\
\hline
\end{tabular}

\section{Summary}

This study sought to obtain students' perspectives on the key aspects that should be addressed when transforming their school culture. Their responses mirrored, "The condition for learning: Key aspects of school climate which support enhanced school academic outcomes: Students are safe, students are supported, students are challenged and students are socially capable," outlined in the Dignity Act (http://www.p12.nysed.gov/dignityact/rgsection1.html).

The students that took part in this study felt that a good school community would make them feel physically, socially and emotionally safe. They want consistent and equitable treatment of all students. They would also like more meaningful out of classroom relationships with their teachers and peers and would like teachers to be available after school for conversation about their homework assignments. They long for positive peer relationships and believe overwhelmingly that they can also change for better. They hope the school will offer them challenging classes and that as much time will be spent on students who want to do well as is currently dedicated to the work with challenging students. They want their school to have after school activities and sports and they strongly believe that this will make their school community a better place.

They report that many of the resources at the school are old and outdated. They are also of view that their school needs updated technology, as well as newer sports equipment. They reported that the school food could be better and more nutritious and that they need better transportation. Some students reported that they have to travel a long distance to reach the school and have to provide their own transportation.

A safe and supportive environment facilitates student learning and success. Collegiality and harmonious relationships between "Town and Gown"-school and the community, students, parents, faculty staff and administration-preserve the dignity all. In an increasingly globalized society, a community or a nation that is not concerned or proactive about the education of all its students, rich and poor, urban or rural, will lag behind in the path toward becoming a full participating member of global societies. Successful implementation of ways and means of educating the young begins with an environment that is conducive to learning. More importantly, education is not geared toward job gains and global competition alone; it is also a collective cultural asset, as an educated populace safeguards democratic traditions and values.

With this initiative, we seek to help a school's transformation through what we believe is the first step, which is to identify the elements of the school climate, its purpose, norms and values that could be changed in order to make the school climate safe and supportive, democratic and conducive to learning.

\section{Recommendation and Limitations}

While this study offered some valuable findings, more research is needed in order to gain a better understanding of what the students feel and need for a healthy school environment. Most importantly, such studies should be conducted from the perspectives of students, as they are the focus of all educational initiatives. Researchers tend to seek input of the administrators, teachers and staff, while overlooking the views of students they serve. It is essential to elucidate what students need to do to contribute to a healthy school climate. As stated earlier, it is through their interactions with their school culture that studeants have most effective impact on their own achievement, their own happiness and academic successes.

The students that took part in this study suggested that they personally want to contribute to healthy schools, but need the adults in their school community to show interest and pay attention to their concerns. They suggest that more attention should be focused on students who are doing well and their successes should be celebrated. Thus, in the future, comparative studies 
between school climate from students' perspectives and students' achievement should be conducted, as their findings can help school principals, teachers and staff focus their efforts on improving student achievement and the goals of attaining healthy school environment.

\section{Acknowledgement}

Our Graduate assistants: Jiaxuan Zong, Ishita Patel and all the students who participated in the survey.

\section{Author's Contributions}

Dolapo Adeniji-Neill: Make considerable contributions to conception, design and acquisition of data, analysis and interpretation of data. Contribute in drafting the article and reviewing it. Critically for significant intellectual content; and give final approval of the version submitted and all revised version.

Devin G. Thornburg: Make considerable contributions to conception and design and acquisition of data. Contribute in drafting the article or reviewing it critically for significant intellectual content; and give final approval of the version submitted and all revised version.

\section{Ethics}

No injuries to humans or animals in the conduct of this survey. Publication of this manuscript should help schools serve their students better by understanding how their students feel about their school climate and culture.

\section{References}

Anderson, C., 1982. The search for school climate: A review of the research. Rev. Educ. Res., 52: 368-420.

Bearden, L.J., W.A. Spencer and J.C. Moracco, 1989. A study of high school dropouts. School Counselor, 37: 113-120.

Borger, J., 1985. Effective schools: A quantitative synthesis of constructs. J. Classroom Interaction, 20: 12-17.
Bryk, A.S. and M. Driscoll, 1988. The high school as community: Contextual influences and consequences for students and teachers. $\mathrm{PhD}$ thesis Madison: University of Wisconsin.

Casel.org, 2008. Retrieved March 17, 2018.

Cohen, J., E. McCabe, N. Michelli and T. Pickeral, 2009. School climate: Research, policy, practice and teacher education. Teachers College Record, 111: 180-213.

Davis, L.E. and H.I. Peck, 1992. Outcome measuresschool climate: Curriculum and instruction. Proceedings of the Annual Meeting of the Mid-South Educational Research Association, (ERA' 92), Knoxville, TN.

Gangi, T., 2009. School climate and faculty relationships: Choosing an effective assessment measure. PhD thesis St John University, New York.

Gruenert, S., 2008. They are not the same thing. National Association Elementary School Principles.

Hoy, W., 2008. School climate - measuring school climate, school climate and outcomes, issues trends and controversies.

Hoy, W.K., C.J. Tarter and R.B. Kottkamp, 1991. Open Schools/Healthy Schools: Measuring Organizational Climate. 1st Edition. Beverly Hills, Sage.

Hoy, W.K. and C.J. Tarter, 1997. The Road to Open and Healthy Schools: A Handbook for Change, Elementary. 1st Edn., Thousand Oaks, Corwin Press.

Kana'iaupuni, S., B. Ledward and U. Jensen, 2010. Culture-Based Education and its Relationship to Student Outcomes. 1st Edition, Kamehameha Schools, Research. 